\title{
Submitted: 1 Association of spectral Doppler cardiac activity Accepted: 24.04.2020 \\ Published: in the lower limb veins and echocardiographic findings in patients with tricuspid regurgitation
} 15.06.2020

\section{Keywords}

tricuspid regurgitation, Doppler echocardiography, spectral Doppler ultrasound, lower limb venous Doppler, right-sided heart failure

\author{
Iqra Manzoor ${ }^{1}$, Syed Amir Gilani², Raham Bacha ${ }^{3}$, Mehreen Fatima ${ }^{4}$ \\ ${ }^{1}$ University Institute of Radiological Sciences and Medical Imaging Technologies, \\ The University of Lahore, Lahore, Pakistan \\ ${ }^{2}$ Dean Faculty of Allied Health Sciences, The University of Lahore, Lahore, Pakistan \\ ${ }^{3}$ University Institute of Radiological Sciences and Medical Imaging Technologies, Faculty \\ of Allied Health Sciences, The University of Lahore, Lahore, Pakistan \\ ${ }^{4}$ University Institute of Radiological Sciences and Medical Imaging Technologies, Faculty \\ of Allied Health Sciences, The University of Lahore, Lahore, Pakistan \\ Correspondence: Dr. Iqra Manzoor, Postal code: 54000, G 1012 Canal Berg, Lahore, Pakistan; \\ tel.+923234622094,e-mail: iqramanzoor36@gmail.com
}

DOI: $10.15557 / \mathrm{JoU} .2020 .0018$

\begin{abstract}
Objective: To determine the association between spectral Doppler cardiac activity in the lower limb veins and echocardiographic findings in patients with tricuspid regurgitation. Material and methods: A cross-sectional analysis was performed in the Gilani Ultrasound Center over a period of 13 months. The total study sample comprised 400 subjects. All individuals referred for abdominal ultrasound having cardiac activities in external iliac vein, popliteal and posterior tibial vein, individuals having normal venous Doppler ultrasound, both genders and all ages, were included, and unwilling and non-cooperative patients were excluded from the study. Results: Out of 400 individuals, 200 showed cardiac activity in the lower limb veins on Doppler vascular ultrasound, while 200 did not show cardiac activity. On echocardiography, 204 individuals were diagnosed with tricuspid regurgitation, and 196 individuals had a competent tricuspid valve. According to the independent sample t-test the mean difference in the posterior tibial vein was 25.54 (95\% CI: 24.09; 26.98), while the mean difference in the iliac vein was 2.34 (95\% CI: 0.64; 4.03) among normal and tricuspid regurgitation. Conclusion: A correlation was found between the cardiac activities in the lower limb veins and tricuspid regurgitation.
\end{abstract}

\section{Introduction}

The most prevalent pathology of the tricuspid valve is tricuspid regurgitation in which the tricuspid valve becomes incompetent ${ }^{(1)}$. There are different causes of tricuspid regurgitation (TR), for example infection including rheumatic fever and infective endocarditis, dilatation of the right ventricle of the heart which in turn causes dilatation of the annulus of the tricuspid valve, and an increased pressure in the tricuspid valve. Other less common causes of tricuspid valve dysfunction include systemic lupus erythematosus, trauma, Ebstein's anomaly, congenital heart defects, carcinoid disease of the heart, prolapse of the tricuspid valve, and tumor of the heart ${ }^{(2)}$. Patients affected by tricuspid regurgitation present with the following symptoms: fatigue, atrial fibrillation, discomfort especially in the neck region, ascites, liver and renal dysfunction, abdominal discomfort and pain, sleeplessness, swelling in the lower limbs, cardiac activities in the veins of the lower limbs, pleural or cardiac effusion, shortness of breath, and cold skin. These symptoms are most commonly associated with severe heart disease $^{(3)}$. The diagnosis of tricuspid valve disease can be 
facilitated by using electrocardiogram (ECG), Doppler echocardiography, magnetic resonance imaging (MRI), radionuclide scan, chest $\mathrm{X}$-ray, transesophageal echocardiography, and cardiac catheterization ${ }^{(4)}$. Tricuspid regurgitation is divided into 3 types which are as follows: primary, secondary, and isolated tricuspid regurgitation. Primary tricuspid regurgitation is caused by an anatomical abnormality of the tricuspid valve ${ }^{(5)}$. Secondary tricuspid regurgitation can be due to the dilatation of the right atrium, right ventricle, tethering of the tricuspid valve, and also due to dilatation of the tricuspid annulus. Disease of the left heart, pulmonary hypertension, atrial fibrillation, which is seen in annular dilatation, are among the causes of isolated tricuspid regurgitation ${ }^{(6)}$. The incidence of tricuspid regurgitation in the United States is $0.9 \%$, and no gender or racial differences are noted ${ }^{(7)}$. Tricuspid regurgitation can occur at any stage in life, while Ebstein's anomaly or primary tricuspid regurgitation can be observed during early childhood or at birth. Another common form of tricuspid regurgitation is rheumatic valvular disease which affects patients over the age of 15 years. At present, echocardiography is recognized as the gold standard in the diagnosis of tricuspid regurgitation ${ }^{(8)}$. Transthoracic echocardiography (TTE), transesophageal echocardiography, and 3-D echocardiography, play a key role in the diagnosis of tricuspid regurgitation. In the initial diagnosis, transthoracic echocardiography plays a fundamental role, while transesophageal echocardiography is applied where transthoracic echocardiography shows poor quality, when the patient has an infection from the pacemaker lead or in other cases like endocarditis $^{(9)}$. On the other hand, 3-D echocardiography is far superior to all of these, as it allows visualization of all the leaflets simultaneously ${ }^{(10)}$. In 2012, guidelines were published by the European Association for Cardiothoracic Surgery (EACTS) and the European Society of Cardiology (ESC) for the staging of tricuspid regurgitation ${ }^{(11)}$. The degree of annular dilatation, mechanism of tricuspid regurgitation, and the presence of tethering, can also be diagnosed with the help of echocardiography. When the annular diameter of the tricuspid valve is $\geq 40 \mathrm{~mm}$, and the average diameter is approximately $21 \mathrm{~mm} / \mathrm{m} 2$ measured at the end-diastole of four-chamber transthoracic view of the heart, this is known as significant tricuspid regurgitation. Significant tethering is attributed to a coaptation distance $>8 \mathrm{~mm}$. Abnormal RV function is attributable to tricuspid annular plane systolic excursion $<1.5 \mathrm{~cm}$ or fractional area shortening $<35 \%{ }^{(12)}$.

Spectral Doppler ultrasound plays a crucial role in providing data about hemodynamic changes in the circulating blood flow. Spectral Doppler information comprises 3 types of variables including time, velocity, and amplitude of sampled circulating blood ${ }^{(13)}$. On the spectral Doppler ultrasound scan, the $\mathrm{X}$-axis depicts the time, $\mathrm{y}$-axis depicts velocity of the moving blood, while the z-axis represents the amplitude. Velocity is the speed at which blood moves in the circulatory system ${ }^{(14)}$. Doppler ultrasound has been used for many years for the diagnosis of various diseases affecting the arteries and veins of the body. Spectral Doppler ultrasound provides additional information about the velocity of the moving blood, and helps in the diagnosis of many lower limb arterial and venous diseases ${ }^{(15)}$. According to one study, the sensitivity and specificity of Doppler ultrasound in the evaluation of different vascular diseases is $97.9 \%$ and $99.5 \%$, respectively ${ }^{(16)}$. On Doppler ultrasound, the blood flow in the veins of the lower limbs is usually phasic, spontaneous, and in the antegrade direction ${ }^{(17)}$. Phasicity in the veins sometimes occurs due to respiratory phasicity which is a normal physiological process, and sometimes cardiac activities are seen in the veins, which is due to pathological conditions including right heart failure, tricuspid regurgitation etc. ${ }^{(18)}$ On spectral Doppler ultrasonography, the blood flow will be seen as pulsatile only due to the failure of the right heart ${ }^{(19)}$. Many studies have been published on phasicity in the spectral Doppler waveform, concluding that if the phasicity in the spectral Doppler waveform occurs for 1 second, then it is cardiac phasicity which is due to an increased pressure in the right atrium ${ }^{(14)}$. As there is no valve between the inferior vena-cava and the right atrium, in cases of tricuspid regurgitation blood flow in the veins in the retrograde direction during ventricular contractions ${ }^{(20)}$. Initially, these cardiac activities remain limited to the central veins, but with time chronic venous insufficiency arises, and could be detected in the lower limb peripheral veins. As stated earlier, tricuspid regurgitation is a reversible condition, and it may resolve if the underlying cause is treated in time $e^{(21)}$. Typically, such patients are unaware of their heart disease (tricuspid regurgitation) ${ }^{(22)}$, and physicians tend to search for renal or hepatic pathologies responsible for the patient's signs and symptoms ${ }^{(20)}$. The purpose of the study was to assess cardiac activities in the lower limb veins in patients with tricuspid regurgitation confirmed by echocardiography ("gold standard"). Moreover, it could be incorporated and used reliably as sonographic criteria when there is no availability or as an adjunct to echocardiography ${ }^{(23,24)}$.

\section{Materials and methods}

A cross-sectional analytical study was performed in the Gilani Ultrasound Center, Lahore, Pakistan, for a duration of 13 months from March 2019 to February 2020. A total sample size of 400 subjects was selected for the purpose of the study. All the individuals referred for abdominal ultrasound having cardiac activities in the external iliac vein, popliteal and posterior tibial veins, individuals having normal venous Doppler ultrasound, both genders of adult age, were included. Unwilling and non-cooperative patients were excluded. Toshiba (Xario), linear transducer with frequency range from 7-14 MHz, and micro-convex transducer with a frequency range of 5 to $9 \mathrm{MHz}$ were used for scanning. Lower limb venous examinations were performed according to the American Institute of Ultrasound in Medicine (AIUM) vascular ultrasound guidelines ${ }^{(25)}$. The lower limb veins were evaluated for cardiac activity based on the spectral Doppler waveform. Then, transthoracic echocardiography was performed with the aid of microconvex transducer. Transthoracic approach was used in the supine position, as part of full echocardiographic assessment $^{(26)}$. Data were collected in the form of information sheets for all required variables including age, gender, 
Tab. 1. Descriptive statistics of variables

\begin{tabular}{|l|l|c|c|}
\hline Variables & Frequency & Percent \\
\hline \multirow{2}{*}{ Gender } & Female & 240 & 60 \\
\cline { 2 - 4 } & Male & 160 & 40 \\
\hline \multirow{2}{*}{ Hypertension } & No & 175 & 43.8 \\
\cline { 2 - 4 } & Yes & 225 & 56.3 \\
\hline \multirow{2}{*}{ Diabetes mellitus } & No & 201 & 50.3 \\
\cline { 2 - 4 } & Yes & 199 & 49.8 \\
\hline \multirow{2}{*}{$\begin{array}{l}\text { Cardiac activity in the } \\
\text { iliac and posterior tibial } \\
\text { veins }\end{array}$} & Normal & 196 & 49.0 \\
\cline { 2 - 4 } & $\begin{array}{l}\text { Tricuspid } \\
\text { regurgitation }\end{array}$ & 204 & 51.0 \\
\hline Total & Present & 200 & 50.0 \\
\hline
\end{tabular}

Tab. 2. Comparison of gender and Doppler echo findings

\begin{tabular}{|l|l|c|c|c|}
\hline \multirow{2}{*}{$\begin{array}{l}\text { Crosstab of gender * } \\
\text { Doppler echo findings }\end{array}$} & \multicolumn{2}{|c|}{ Doppler echo findings } & \multirow{2}{*}{ Total } \\
\cline { 3 - 4 } & Normal & $\begin{array}{c}\text { Tricuspid } \\
\text { regurgitation }\end{array}$ & \\
\hline \multirow{2}{*}{ Gender } & Female & $124(31.0 \%)$ & $116(29.0 \%)$ & $240(60.0 \%)$ \\
\cline { 2 - 5 } & Male & $72(18.0 \%)$ & $88(22.0 \%)$ & $160(40.0 \%)$ \\
\hline Total & $196(49.0 \%)$ & $204(51.0 \%)$ & $400(100.0 \%)$ \\
\hline
\end{tabular}

Tab. 3. Comparison of diabetes mellitus and Doppler echo findings

\begin{tabular}{|l|l|c|c|c|}
\hline \multirow{2}{*}{ Crosstab } & \multicolumn{2}{|c|}{ Doppler echo findings } & \multirow{2}{*}{ Total } \\
\cline { 3 - 4 } \multicolumn{2}{|l|}{} & Normal & $\begin{array}{c}\text { Tricuspid } \\
\text { regurgitation }\end{array}$ & \\
\hline $\begin{array}{l}\text { Diabetes } \\
\text { mellitus }\end{array}$ & No & $137(34.3 \%)$ & $64(16.0 \%)$ & $201(50.3 \%)$ \\
\cline { 2 - 5 } & Yes & $59(14.8 \%)$ & $140(35.0 \%)$ & $199(49.8 \%)$ \\
\hline Total & $196(49.0 \%)$ & $204(51.0 \%)$ & $400(100.0 \%)$ \\
\hline
\end{tabular}

occupation, tricuspid regurgitation, cardiac activities in the lower limb veins, hypertension, and diabetes. Data analysis was performed with the help of Microsoft Excel 2018 and Statistical Package for the Social Sciences, version 24 (SPSS 24, IBM, Armonk, NY, United States of America). The chi-square test and correlation of tricuspid regurgitation and cardiac activities in the iliac and posterior tibial veins were applied. Qualitative data, e.g. hypertension, diabetes, gender, occupation, cardiac activities in the iliac and posterior tibial veins, and tricuspid regurgitation were presented in the form of frequencies and their respective percentages. Demographic data such as age were presented in the form of mean \pm standard deviation.

\section{Results}

Four hundred individuals were selected for the study, with the mean age of $37 \pm 12$ years, ranging from 1 to 97 . The total number was divided into two groups: normal individuals and patients with tricuspid regurgitation. Out of the total number of participants, 200 individuals showed cardiac activity in the lower limb vein on Doppler vascular ultrasound, while 200 individuals did not show cardiac activity. Among them, 204 (51.0\%) individuals were diagnosed with tricuspid regurgitation, and 196 (49\%) individuals showed competent tricuspid valve (Tab. 1). Out of the total number of included individuals, $240(60 \%)$ were females and 160 (40\%) were males (Tab. 2). Details related to diabetes mellitus in normal individuals and patients with tricuspid regurgitation are given in (Tab. 3). In the normal group, the mean age of the individuals was 37.33 with a range of 5.00-87.00 $\pm 16.29 \mathrm{Std}$. D, while the mean age in the patients with tricuspid regurgitation was 55.92 with a range of 1.00-97.00 \pm 19.49 Std. D. In the normal group, the mean velocity in the posterior tibial vein was $5.59 \mathrm{~cm} / \mathrm{s}$, with a range of $3.10-8.90 \mathrm{~cm} / \mathrm{s} \pm 1.57 \mathrm{Std}$. D, while in the patients with tricuspid regurgitation the mean velocity in the posterior tibial vein was $31.13 \mathrm{~cm} / \mathrm{s}$, with a range of $4.20-59.20 \mathrm{~cm} / \mathrm{s} \pm 10.19$ Std. D. On the other hand, in the normal group the mean velocity in the iliac vein was $39.82 \mathrm{~cm} / \mathrm{s}$, with a range of $30.10-49.30 \mathrm{~cm} / \mathrm{s} \pm 5.50 \mathrm{Std}$. $\mathrm{D}$, while in patients with tricuspid regurgitation the mean velocity in the iliac vein was $42.16 \mathrm{~cm} / \mathrm{s}$, with a range of $10.90-69.80 \mathrm{~cm} / \mathrm{s} \pm 10.81 \mathrm{Std}$. D (Tab. 4). The subjects included in the study represent different professions. Both the healthy group and patients with tricuspid regurgitation have various occupations, which were divided into 4 classes as follows: housewives, students, unemployed and others including a carpenter, clerk, driver, electrician, farmer, gardener, laborer, manager, mason, nurse, office worker, plumber, property dealer, retired, salesman, street hawker, teacher, writer (Tab. 5).

\section{Discussion}

Doppler echocardiography is currently considered to be the most valuable and definitive tool in the assessment of different heart diseases including valvular regurgitation, and its sensitivity and specificity are comparable to cineangiography ${ }^{(27)}$. A literature review shows that Doppler echocardiography is more sensitive than cardiac auscultation, particularly in cases where valvular regurgitation is mild ${ }^{(28)}$. Doppler echocardiography is also able to detect a milder degree of regurgitation in the early stages of the disease, when there are not yet any visible symptoms ${ }^{(29)}$. Lower limb

Tab. 4. Velocity in posterior tibial vein $(\mathrm{cm} / \mathrm{s})$ and velocity in iliac vein $(\mathrm{cm} / \mathrm{s})$

\begin{tabular}{|l|l|c|c|c|}
\hline \multicolumn{2}{|l|}{ Doppler echo findings } & Age (years) & $\begin{array}{c}\text { Velocity } \\
\text { in posterior } \\
\text { tibial vein } \\
\text { cm/s }\end{array}$ & $\begin{array}{c}\text { Velocity } \\
\text { in iliac vein } \\
\text { cm/s }\end{array}$ \\
\hline \multirow{4}{*}{ Normal } & Mean & $37.33 \pm 16.29$ & $5.59 \pm 1.57$ & $39.82 \pm 5.50$ \\
\cline { 2 - 6 } & $\mathrm{N}$ & 196 & 196 & 196 \\
\cline { 2 - 6 } & Minimum & 5 & 3.10 & 30.10 \\
\cline { 2 - 6 } & Maximum & 87 & 8.90 & 49.30 \\
\hline \multirow{5}{*}{ regurgitation } & Mean & $55.92 \pm 19.49$ & $31.13 \pm 10.19$ & $42.16 \pm 10.81$ \\
\cline { 2 - 6 } & N & 204 & 204 & 204 \\
\cline { 2 - 6 } & Minimum & 1 & 4.20 & 10.90 \\
\cline { 2 - 6 } & Maximum & 97 & 59.20 & 69.80 \\
\hline \multirow{5}{*}{ Total } & Mean & $46.81 \pm 20.24$ & $18.61 \pm 14.74$ & $41.01 \pm 8.70$ \\
\cline { 2 - 6 } & N & 400 & 400 & 400 \\
\cline { 2 - 6 } & Minimum & 1 & 3.10 & 10.90 \\
\cline { 2 - 6 } & Maximum & 97 & 59.20 & 69.80 \\
\hline
\end{tabular}


Tab. 5. Occupations of patients

\begin{tabular}{|l|l|c|c|c|}
\hline \multicolumn{2}{|c|}{ Crosstab } & \multicolumn{2}{|c|}{ Doppler echo findings } & \multirow{2}{*}{ Total } \\
\cline { 3 - 5 } \multicolumn{2}{|c|}{} & Normal & $\begin{array}{c}\text { Tricuspid } \\
\text { regurgitation }\end{array}$ & \\
\hline \multirow{4}{*}{ Occupation } & Housewife & $50(12.5 \%)$ & $43(10.8 \%)$ & $93(23.3 \%)$ \\
\cline { 2 - 5 } & Unemployed & $21(5.3 \%)$ & $69(17.3 \%)$ & $90(22.5 \%)$ \\
\cline { 2 - 5 } & Student & $3(0.8 \%)$ & $2(0.5 \%)$ & $5(1.3 \%)$ \\
\cline { 2 - 5 } & Others & $54(64.4 \%)$ & $76(67.9 \%)$ & $130(32.4 \%)$ \\
\hline \multicolumn{1}{|l|}{ Total } & $196(49.0 \%)$ & $204(51.0 \%)$ & $400(100.0 \%)$ \\
\hline
\end{tabular}

venous Doppler sonography is recognized as the standard screening test. However, researchers disagree on the nature of phasicity of venous Doppler waveforms. Some think this phasicity is cardiac in origin, reflecting changes in right atrium pressure; others argue that the changes are respiratory; a third group describes the phasicity as sometimes respiratory and sometimes $\operatorname{cardiac}^{(30)}$. The disagreement reflects a lack of understanding, which leads to a lack of interest, and consequently a scarcity of reports addressing the significance of the pulsatile flow in these waveforms ${ }^{(31)}$. The aim of the study was to diagnose cardiac abnormalities of the right heart with the help of Doppler ultrasonography of the lower limb veins. The authors attempted to quantify the degree of TR by evaluating the waveform of the femoral vein. The Doppler waveforms of the lower extremity veins were evaluated in 276 patients over a period of 17 months. The abnormal pulsatile Doppler waveforms recorded in these patients were compared with the echocardiography findings. The chest radiographs (CXR) of 104 patients out of 276 were reviewed. According to the findings, abnormal cardiac activity of Doppler waveforms was noted in 9 patients $(3.3 \%)$, with abnormally high retrograde velocity peaks. These abnormal retrograde velocity peaks were compared with the retrograde velocity peaks in the control group. The retrograde velocity peaks in the diseased group show a statistically significant (Pearson's $r=0.9113$ ) correlation with the degree of tricuspid regurgitation observed on echocardiography. All of the 9 patients showed enlargement of the heart on chest radiographs, compared to 16 out of $95(16.8 \%)$ with a normal Doppler waveform. It was concluded that spectral Doppler ultrasound is routinely performed in the hospital radiology departments, and it is a quite simple, reliable, and reproducible method for the evaluation of the veins in lower limbs, and their abnormalities. The sonologist is able to detect the degree of tricuspid regurgitation if cardiac activity is seen within the veins of the lower limbs ${ }^{(23)}$. In the reported study, 400 individuals were included, of which 200 individuals showed cardiac activity in the lower limb vein on Doppler vascular ultrasound, while 200 individuals did not show cardiac activity. Among 400 subjects, 204 were diagnosed with tricuspid regurgitation, and 196 subjects showed a competent tricuspid valve. The results of the study were also statistically significant, having the $p$-value $=0.00$ and $<0.001$. According to the results of previous studies, age is weakly correlated with tricuspid regurgitation. However, according to the present study, the correlation is strong, with more identified patients at an advanced age compared to young individuals ${ }^{(32)}$.

\section{Conclusion}

An association was found between the cardiac activities in the lower limb veins and tricuspid regurgitation.

\section{Conflict of interest}

Authors do not report any financial or personal connections with other persons or organizations which might negatively affect the contents of this publication and/or claim authorship rights to this publication.

\section{References}

1. Utsunomiya H, Itabashi Y, Mihara H, Berdejo J, Kobayashi S, Siegel RJ et al.: Functional tricuspid regurgitation caused by chronic atrial fibrillation: a real-time 3-dimensional transesophageal echocardiography study. Circ Cardiovasc Imaging 2017; 10: e004897.

2. Vassileva CM, Shabosky J, Boley T, Markwell S, Hazelrigg S: Tricuspid valve surgery: the past 10 years from the Nationwide Inpatient Sample (NIS) database. J Thorac Cardiovasc Surg 2012; 143: 1043-1049.

3. Sadeghpour A, Hassanzadeh M, Kyavar M, Bakhshandeh H, Naderi N, Ghadrdoost B et al.: Impact of severe tricuspid regurgitation on long term survival. Res Cardiovasc Med 2013; 2: 121-126.

4. Arsalan M, Walther T, Smith RL, Grayburn PA: Tricuspid regurgitation diagnosis and treatment. Eur Heart J 2017; 38: 634-638.

5. Lancellotti P, Moura L, Pierard LA, Agricola E, Popescu BA, Tribouilloy C et al.: European Association of Echocardiography recommendations for the assessment of valvular regurgitation. Part 2: mitral and tricuspid regurgitation (native valve disease). Eur J Echocard 2010;11: 307-332.

6. Mas PT, Rodríguez-Palomares JF, Antunes MJ: Secondary tricuspid valve regurgitation: a forgotten entity. Heart 2015; 101: 1840-1848.

7. Lee RC, Friedman SE, Kono AT, Greenberg ML, Palac RT: Tricuspid regurgitation following implantation of endocardial leads: incidence and predictors. Pacing Clin Electrophysiol 2015; 38: 1267-1274.

8. Song J-M, Jang M-K, Choi Y-S, Kim Y-J, Min S-Y, Kim D-H et al.: The vena contracta in functional tricuspid regurgitation: a real-time threedimensional color Doppler echocardiography study. J Am Soc Echocardiogr 2011; 24: 663-670.

9. Hon JKF, Cheung A, Ye J, Carere RG, Munt B, Josan Ket al.: Transatrial transcatheter tricuspid valve-in-valve implantation of balloon expandable bioprosthesis. Ann Thorac Surg 2010; 90: 1696-1697.

10. Kim J, Lee M, Lee JY, Lee JY, Choi KH, Lim SH et al.: Traumatic tricuspid valve detachment from annulus diagnosed on 3-D transesophageal echocardiography. Circ J 2014; 78: 259-261.

11. Joint Task Force on the Management of Valvular Heart Disease of the European Society of Cardiology (ESC), European Association for Cardio-Thoracic Surgery (EACTS), Vahanian A, Alfieri O, Andreotti F, Antunes MJ et al.: Guidelines on the management of valvular heart disease (version 2012). Eur Heart J 2012; 33: 2451-2496.

12. Goldstone AB, Howard JL, Cohen JE, MacArthur Jr JW, Atluri P, Kirkpatrick JN et al.: Natural history of coexistent tricuspid regurgitation in patients with degenerative mitral valve disease: implications for future guidelines. J Thorac Cardiovasc Surg 2014; 148: 2802-2810.

13. Wood MM, Romine LE, Lee YK, Richman KM, O'Boyle MK, Paz DA et al.: Spectral Doppler signature waveforms in ultrasonography: a review of normal and abnormal waveforms. Ultrasound Q 2010; 26: 83-99. 
14. Barleben A, Bandyk DF: Interpretation of peripheral venous duplex testing. Semin Vasc Surg 2013; 26: 111-119.

15. Hoskins PR, Martin K, Thrush A: Diagnostic ultrasound: physics and equipment. CRC Press. 2019.

16. Kayılıoğlu SI, Köksoy C, Alaçayır İ: Diagnostic value of the femoral vein flow pattern for the detection of an iliocaval venous obstruction. J Vasc Surg Venous Lymphat Disord 2016; 4: 2-8.

17. Sirous M, Sirous R, Nejad FK, Rabeie E, Mansouri M: Evaluation of different aspects of power Doppler sonography in differentiating and prognostication of breast masses. J Res Med Sci 2015; 20: 133-139.

18. Sanford DA, Kelly D, Rhee SJ, Stoughton J, Cantelmo NL: Importance of phasicity in detection of proximal iliac vein thrombosis with venous duplex examination. J Vasc Ultrasound 2011; 35: 150-152.

19. Begelman SM, Yesenko SL: Duplex ultrasound imaging of iliac venous stents. J Vasc Ultrasound 2003; 27: 101-105.

20. Houle M, Neuhardt DL, Straight NT, Salles-Cunha SX: Differences in saphenous vein reflux detection according to patient positioning. J Vasc Ultrasound 2013; 37: 81-84.

21. da Cunha Júnior JR, Neves DQ, Fontes FA, Solano GP, Cardoso MCT, de Lima MH et al.: Endovascular treatment of iliac vein compression syndrome (May-Thurner) - a case report. J Vasc Brasil 2011; 10: 72-76.

22. Bechtel G, Burr M, Bendick P: Venous claudication secondary to extrinsic iliac vein compression managed by endoluminal stenting: diagnosis and follow-up using duplex ultrasound. J Vasc Technol 2001; 25: $125-148$

23. McClure MJ, Kelly BE, Campbell NS, Blair PH: Duplex Doppler ultrasonography of lower limb veins: detection of cardiac abnormalities. Clin Radiol 2000; 55: 533-536.

24. Coleridge-Smith P, Labropoulos N, Partsch H, Myers K, Nicolaides A, Cavezzi A: Duplex ultrasound investigation of the veins in chronic venous diseases of the lower limbs - UIP consensus document. Part I. Basic principles. Vasa 2007; 36: 53-61.
25. Barnett SB, Maulik D, International Perinatal Doppler Society: Guidelines and recommendations for safe use of Doppler ultrasound in perinatal applications. J Matern Fetal Med 2001; 10: 75-84.

26. Mohler ER, Gornik HL, Gerhard-Herman M, Misra S, Olin JW, Zierler RE: ACCF/ACR/AIUM/ASE/ASN/ICAVL/SCAI/SCCT/SIR/SVM/SVS 2012 appropriate use criteria for peripheral vascular ultrasound and physiological testing part I: arterial ultrasound and physiological testing: a report of the American College of Cardiology Foundation appropriate use criteria task force, American College of Radiology, American Institute of Ultrasound in Medicine, American Society of Echocardiography, American Society of Nephrology, Intersocietal Commission for the Accreditation of Vascular Laboratories, Society for Cardiovascular Angiography and Interventions, Society of Cardiovascular Computed Tomography, Society for Interventional Radiology, Society for Vascular Medicine, and Society for Vascular Surgery. J Am Coll Cardio 2012; 60: 242-276.

27. Schroedter WB, White JM, Garcia AR, Ellis ME: Presence of lowerextremity venous pulsatility is not always the result of cardiac dysfunction. J Vasc Ultrasound 2014; 38: 71-75.

28. Blanco P, Volpicelli G: Common pitfalls in point-of-care ultrasound: a practical guide for emergency and critical care physicians. Crit Ultrasound J 2016; 8: 15.

29. Lee ST, Lin MH: Color Doppler echocardiographic assessment of valvular regurgitation in normal infants. J Formos Med Assoc 2010; 109: 56-61.

30. Dalla Vestra M, Grolla E, Bonanni L, Dorrucci V, Presotto F, Rigo F: From the veins to the heart: a rare cause of varicose veins. Case Rep Vasc Med 2015; 2015: 849408.

31. Schroedter WB, White JM, White BD, Mauriello JD, Sanchez E, Izzo Jr EG: Does distal venous hypertension affect lower-extremity venous pulsatility? J Vasc Ultrasound 2011; 35: 72-76.

32. Marra AM, Naeije R, Ferrara F, Vriz O, Stanziola AA, D'Alto M et al.: Reference ranges and determinants of tricuspid regurgitation velocity in healthy adults assessed by two-dimensional doppler-echocardiography. Respiration 2018; 96: 425-433. 